0
acrl 2013 peer revered
APRIL 10-13
Indianapolis, Indiana

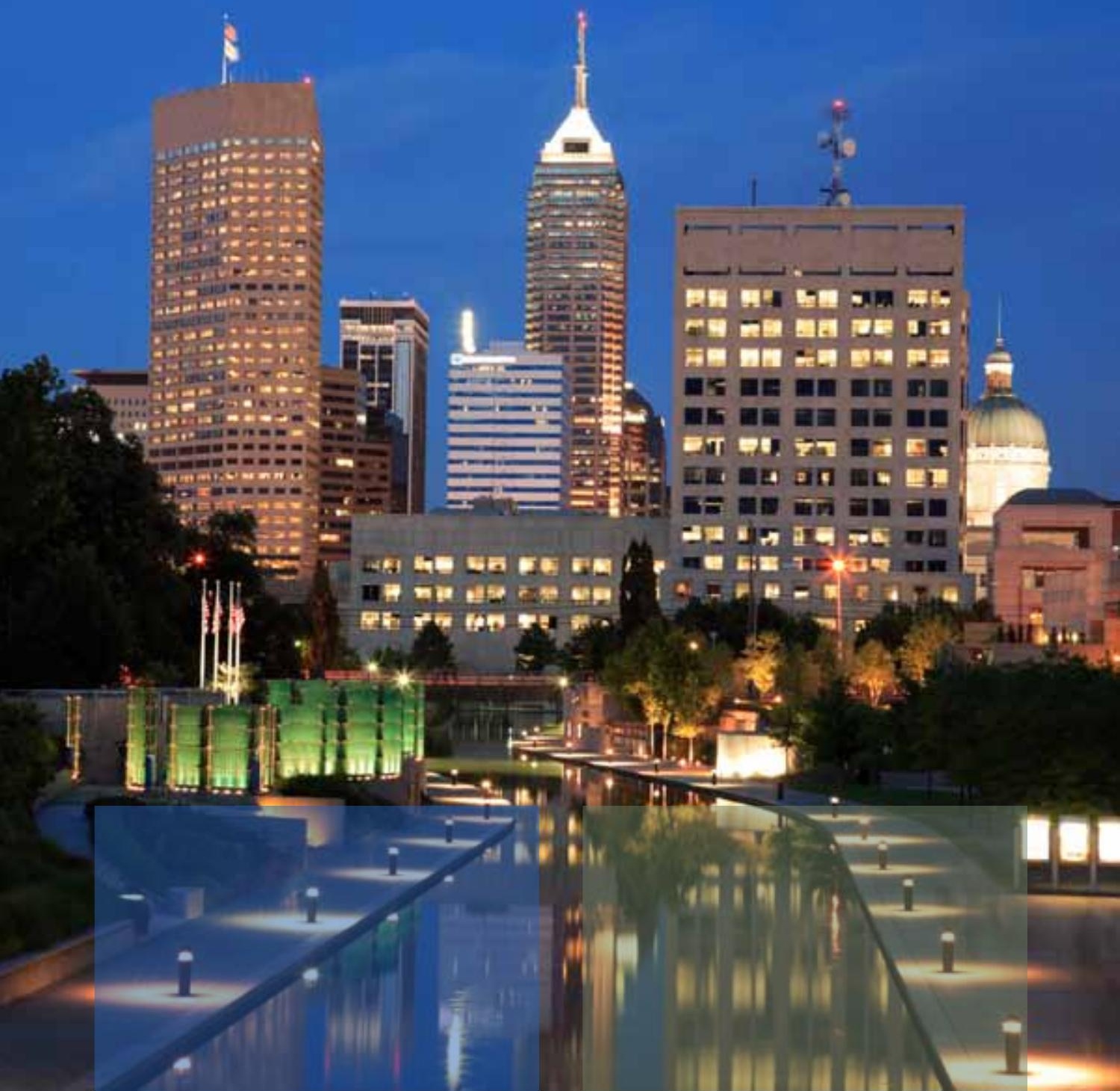

\title{
call for participation
}

Imagine, Innovate, Inspire 


\section{call for participation}

Imagine a future where we explore innovative methods for driving the transformation of libraries, learning, and research, and inspire academic and research libraries and librarians to become catalysts in exceptional research and learning. That future is now, and the Association of College and Research Libraries (ACRL) challenges you to become part of this future by participating in the ACRL 2013 conference to be held in Indianapolis, Indiana, April 10-13, 2013.

The ACRL Plan for Excellence envisions a future where academic and research librarians and libraries are indispensable to a thriving global community of learners and scholars. The ACRL 2013 committee invites you to help realize this vision by submitting a proposal for ACRL 2013: Imagine, Innovate, Inspire. We challenge you to imagine, innovate, and inspire your colleagues and others in the higher education community with proposals that explore the most dynamic and challenging issues and ideas facing academic and research librarians today.

The ACRL 2013 committee assembled a list of 40 tags to describe many of these compelling issues. We invite you to submit proposals and tag them with up to three keywords. These issues and topics will provide a framework for us to think about how we can advance our field and consider practical strategies to help us achieve these advancements. The tagging system will emphasize connections among the conference content and help all participants identify and sort through the wide variety of dynamic interactions and exchanges that define ACRL conferences.

In addition to formal professional development and learning opportunities presented at ACRL 2013, the conference offers informal time with colleagues to enjoy the exciting attractions, restaurants, historical landmarks, and shopping districts that Indianapolis has to offer. We will continue to offer the popular ACRL Virtual Conference, and embrace the innovative use of social networking tools in order to expand and amplify the experience of the event. We invite you to contribute your ideas to ACRL 2013 and be part of the conference that inspires transformation in libraries, learning, and research.

\section{conference tags}

Access services

Advocacy

Assessment

Budgets

Campus-wide initiatives

Collaboration

Collections

Data curation/management

Digital humanities

Discovery \& delivery

Distance learning

Diversity

E-books

Electronic resources
Emerging technologies

First-year experience

Fundraising/development

Hot topics/wild card

Information literacy

Innovation

Intellectual freedom

Intellectual property \& copyright

Leadership \& management

Mentoring

Metadata \& cataloging

Mobile technologies

Organizational change

Outreach/engagement
Professional/staff development Public services

Reference

Scholarly communication

Social media

Space/buildings

Special collections

Teaching \& learning

Technical services

Technology

Trends \& forecasting

User experience

Value/impact 


\section{session formats}

\section{Contributed Papers}

The Contributed Papers committee invites research and position papers that challenge current assumptions and provoke conference participants to think creatively about issues facing academic and research librarians. Papers may report the results of completed research, describe research in progress, or present a position on a compelling problem or issue relevant to one or more of the conference tags. Research papers should highlight the problem, results, and conclusions while very briefly touching on method. Conference tags provide a construct for organizing the papers into groups, and authors may propose works that cover up to three tags. In an effort to maximize interactivity and to provide more opportunities for participation, papers will be grouped in threes, and each paper must be delivered in a maximum of 12 minutes, with an additional 7 minutes for questions (20 minutes total) within a 60-minute time slot for all three papers.

Completed papers should be about 2,500 words and should be scholarly, well organized, clearly written, and rigorously argued. Completed papers must be provided no later than February 18, 2013. The paper should be prepared according to The Chicago Manual of Style and should include a bibliography of cited references (in addition to the 2,500 words). Please note that at the conference, presenters are expected to discuss their ideas rather than read their papers. All accepted papers will be published in the online conference proceedings.

\section{Cyber Zed Shed Presentations}

Do you look at new technologies and wonder how they can help your students and faculty? Does re-purposing existing technologies to solve new problems get you excited? Have you found creative ways to harness technology for the success of your users? Share your innovations with your colleagues, library administrators, and others at ACRL 2013. The ACRL 2013 Cyber Zed Shed Committee invites proposals that document technology-related innovations in every area of the library, from instruction to ILL, reference to reserves, outreach to outsourcing. Cyber Zed Shed presentations are 20 minutes, with 15 minutes to present a demonstration, and 5 additional minutes for audience Q\&A. Presentations should document technologyrelated innovations in academic and research libraries. A computer, data projector, screen, microphone, and stage will be provided. You will be responsible for bringing all other equipment required for your demonstration, except as agreed to in advance. 


\section{acrl 2013 APRIL 10-13 peer revered \\ Indianapolis, Indiana}

\section{Panel Sessions}

Panel sessions bring together the perspectives of two to three presenters into a cohesive conversation of innovative ideas, current topics, and salient issues regarding the evolving and transformative nature of academic and research libraries. Lasting one hour (including time for Q\&A), these sessions are intended to engage audience members in thinking about or participating in discussions surrounding the multiple perspectives presented and their potential impact on current and future professional practice. Sessions will be selected based on their relevance to academic libraries and librarianship; clarity of purpose and intended outcomes for the audience; and the overall contribution to the conference as a mechanism for moving the profession forward.

\section{Poster Sessions}

Got an innovative library-based project, a best practice to solve a problem, or unique research findings? Share them in a poster session! Posters should be an eye-catching visual representation of a topic, including graphics, tables, charts, text, and images (additional details can be shared via online handouts). Presenters share their ideas as attendees circulate during one-hour time blocks in the poster session area, located in the exhibits hall. Since space is limited at a poster session, a maximum of two presenters per poster at any one time is recommended. The Poster Session committee looks for topics that will engage attendees during repeated presentations. Give us the highlights and the "so what?" in the short description. Best practices for a successful poster session will be available prior to the conference.

\section{Preconferences}

Preconferences are half-day or full-day programs that focus on a particular subject of interest to academic and research librarians. These programs should allow participants to develop a skill on a specific topic and should focus on interactive learning using a variety of presentation styles. Preconferences that offer practical tips and cutting-edge techniques, as well as programs that address one or more of the conference's themes, are especially encouraged. Preconferences have separate registration fees, so please contact Margot Conahan at ACRL (312-280-2522; mconahan@ala.org) during the development of your proposal in order to develop a budget for your session. 


\section{Roundtable Discussions}

Roundtables are small, informal group discussions that give attendees the opportunity to exchange information, discuss best practices, and network with others around common themes and issues. Discussion facilitators should identify and develop a topic that will allow participants to discuss how they are dealing with specific issues at their libraries. Roundtable discussions are limited to ten individuals per table, including participants and facilitator. Individuals submitting roundtable proposals should address the topics to be covered, their importance to academic libraries, and three questions they would use to keep the discussion moving.

\section{Virtual Conference Webcasts}

A vital part of the Virtual Conference, Webcasts are synchronous online presentations allowing presenters to interact with virtual attendees in real-time via audio, video, and screen share. This option is perfect for those searching for opportunities to participate in ACRL 2013 online, alleviating concerns about time and travel. Sessions will be selected for presentation based on relevance, timeliness of topic, and clear, intriguing proposals. Webcasts are 60 minutes (including Q\&A) and should be specifically designed for virtual presentation. In their proposal, submitters should explain how they will use the Webcast environment to create interactivity among the attendees. In order to present a successful Webcast, advance preparation and practice are critical; speaker orientations will show how to use the software and provide tips on creating a virtual presentation. Webcast presenters will be required to submit materials in a timely manner. Webcast presenters can offer their session either from the face-to-face conference or remotely. Required technology includes a computer with a high-speed Internet connection and microphone.

\section{Workshops}

Workshops offer three contact hours that provide active and in-depth learning. Participants will engage an issue, learn a new skill, or develop an action plan or other activity where hands-on learning is integral. Proposals should allow for significant involvement and contribution to the learning process from the participants. Proposals will be selected for the conference based on the timeliness of the topic, the stated learning outcomes, drafts of interactive exercise(s), and the degree of active learning.

In order to ensure that the sessions really are "hands-on" and provide participants with a tangible skill or action plan by the end of the session, submissions must include an example of an activity or worksheet you plan to provide. The learning experience should excite and encourage the participants to take risks, question assumptions, and fully engage in the learning process. Participants should leave the session with information to share with their home institutions. Sessions will be limited to 60 participants in order to provide a meaningful environment for active learning. 


\section{HOW TO SUBMIT PROPOSALS}

Proposals must be submitted via the Program Proposal Form, available online at www.acrl.org/acrlconference (click "Program").

\section{deadlines}

May 11, 2012

Proposals due for contributed papers, panel sessions, workshops, and preconferences

November 9, 2012 Proposals due for cyber zed shed presentations, poster sessions, roundtable discussions, and virtual conference Webcasts

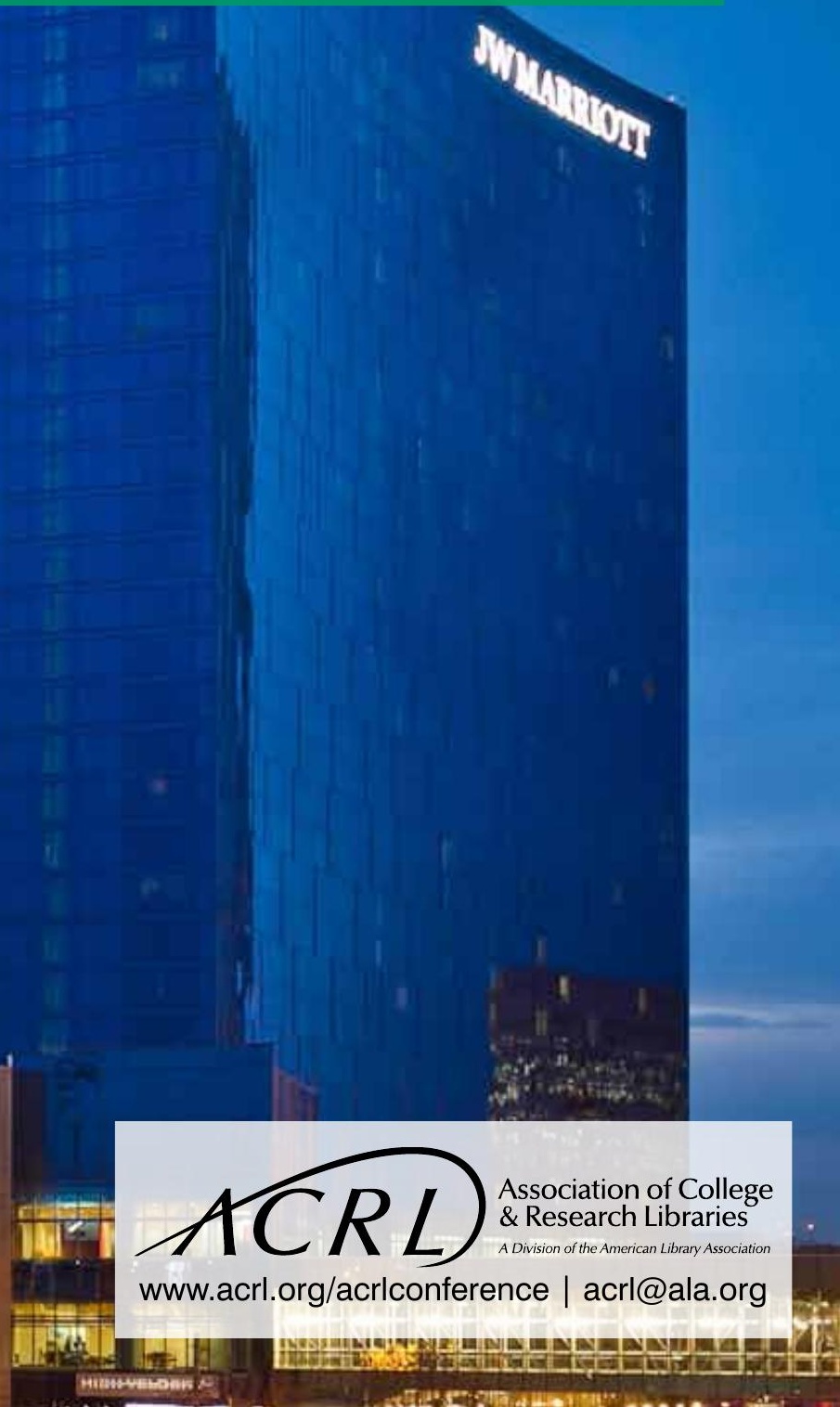

